\title{
Pengembangan Sistem Informasi Inventori Barang Berbasis Website Menggunakan Model Rapid
}

\author{
Muhamad Zaki, Adi Saputra ${ }^{1}$, Ahmad Syauqie Syahrizan ${ }^{2}$, Sandi Ocviana ${ }^{3}$, Yulianti ${ }^{4}$ \\ Teknik Informatika, Universitas Pamulang, Tangerang Selatan, Indonesia \\ e-mail: ${ }^{1}$ muhamadzaki761@gmail.com, ${ }^{2}$ adi9243@gmail.com, ${ }^{3}$ ahmadstauqiesyahriza@gmail.com, \\ ${ }^{4}$ sandiocviana123@gmail.com, ${ }^{5}$ yulianti@unpam.ac.id \\ Submitted Date: November $18^{\text {th }}, 2020$ \\ Revised Date: March 31 $1^{\text {st }}, 2021$ \\ Reviewed Date: November $23^{\text {rd }}, 2020$ \\ Accepted Date: April 01 ${ }^{\text {st }}, 2021$
}

\begin{abstract}
Within a company, data processing is very important for a company to take place. But many companies do not have good data processing. There are still many things that cause data processing errors. Including in PT. Indojaya Multi works, data processing in this company including poor data processing so that there are still many errors that have occurred. Pt. Indojaya Mukti Karya is one of the companies established in Indonesia that provides goods and serves the implementation of the project that is shiny floor. Therefore, we try to develop data processing in the company to be better and efficient. In order to avoid mistakes that have occurred, for that we develop an Inventory system that has several features such as goods forms, clients, suppliers, warehouses and QR codes. In its application this information system is created using the programming language html, css, java script, php and database. And so this information system aims to minimize data processing errors in the company.
\end{abstract}

Keywords: System design, data, inventory, rapid, website

\begin{abstract}
Abstrak
Di dalam sebuah perusahaan, pengolahan data sangatlah penting untuk berlangsung nya sebuah perusahaan. Namun banyak perusahaan yang tidak memiliki pengolahan data yang baik. Masih banyak hal-hal yang menyebabkan kesalahan pengolahan data. Termasuk di PT. Indojaya Multi karya, pengolahan data di perusahaan ini termasuk pengolahan data yang kurang baik sehingga masih banyak yang kesalahankesalahan yang telah terjadi. PT. Indojaya Multi Karya adalah salah satu perusahaan yang berdiri di Indonesia yang menyediakan barang dan melayani pelaksanaan proyek yaitu mengkilapkan lantai. Maka dari itu kami mencoba mengembangkan pengolahan data di perusahaan tersebut agar lebih baik dan efisien. Agar dapat menghindari kesalahan-kesalahan yang telah terjadi, Untuk itu kami mengembangkan sistem Inventaris yang memiliki beberapa fitur seperti formulir barang, klien, pemasok, gudang dan code QR. Dalam penerapan nya sistem informasi ini dibuat menggunakan bahasa pemrograman html, css, java script, php dan database. Dan sehingga sistem informasi ini bertujuan untuk meminimalisir kesalahan-kesalahan pengolahan data pada perusahaan tersebut.
\end{abstract}

Kata Kunci: Perancangan sistem, data, inventaris, rapid, website

\section{Pendahuluan}

PT. Indojaya Multi Karya adalah salah satu perusahaan yang berdiri di Indonesia yang menyediakan barang dan melayani pelaksanaan proyek yaitu mengkilapkan lantai. Karya ilmiah ini bertujuan untuk membantu perusahaan tersebut dalam pengolahan data. Sehingga pengolahan data tersebut dapat diminimalisir dari kesealahan-kesalahan yang telah terjadi (Pratama, 2014).
Dalam pengolahan data sistem gudang atau pun pengolahan data yang lainnya, PT. Indojaya Multi Karya masih melakukan pencatatan menggunakan cara manual yaitu dengan mencatat pengeluaran material, stok persediaan material, dan memasukan kedalam Microsoft exel sehingga sangat tidak efisien ketika melakukan pelaporan secara berkala, dengan cara manual saat ini perusahaan sulit untuk mengetahui data pengeluaran, ketersediaan 
barang, serta data barang masuk dari suplaier, untuk mengatasi masalah tersebut perusahaan mengembangkan sebuah sistem informasi untuk meningkatkan efisiensi waktu dalam produktifitas serta dapat menghemat waktu dan biaya opersional.

PT. Indojaya Multi Karya merupakan perusahan yang bergerak dalam jasa Epoxy dan Coating pada lantai kerja. dalam kesehariannya PT. Indojaya Multi Karya sering menemukan permasalahan diantaranya yang sering terjadi adalah pada saat proses pengiriman barang ke konsumen administrasi gudang membuat data secara manual dan laporan yang dicatat terkadang tidak sama antara data persediaan barang, data barang keluar, data barang masuk, sehingga ketika dilacak tidak dapat diketahui, dengan masalah seperti ini mendorong perusahaan untuk mengembangkan sistem informasi ini untuk membantu mencatat data dan laporan agar tidak terjadi kesalahan dalam laporan stok gudang serta dapat membuat efisien pekerjaan.

Metode usulan yang akan di kembangkan yaitu inventori dengan menggunakan model rapid application development (A Aswati, 2016). Inventori merupakan sebuah konsep dalam menggambarkan sumber daya di suatu perusahaan baik yang dapat digunakan ataupun belum dipergunakan. Dengan adanya sebuah sistem informasi inventori pada perusahaan diharapkan dapat mempermudah membantu menyajikan laporan sebuah informasi keluar, masuk dan stok barang dalam persediaan. Dengan model rapid application development pengembangan sistem informasi ini dapat diselesaikan dengan tahapan perancangan yang lebih singkat sehingga dalam pembuatan serta perancangan sistem informasi ini dapat terselesaikan dengan tidak banyak memakan waktu (Hidayati, 2018).

Dalam upaya menyelesaikan masalah tersebut PT. Indojaya Multi Karya mencoba mengembangkan sebuah sistem informasi yang mampu menyelesaikan permasalahan perancangan dan pengembangan sebuah sistem informasi. Pengembang ini mengunakan metode Rapid Application Development dengan metode tersebut pengembangan sistem dilakukan secara sederhana sesuai kebutuhan pada perusahaan dan sistem dapat bermanfaat dengan baik (McLeod, 2001).

\section{Metodologi}

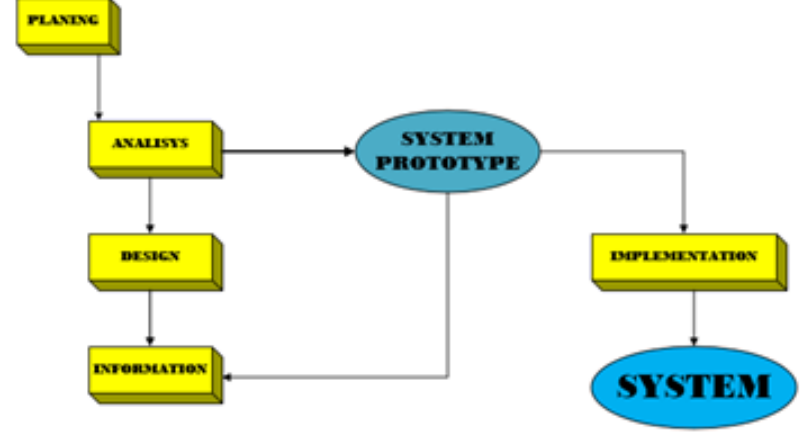

Gambar 1. Metode Rapid

Pada perancangan sistem inventory PT Indojaya Multi Karya digunakan metodologi Rapid Development metodologi ini merupakan bagian dari sebuah sistem development life cycle di mana tahapan-tahapan perancangan dan pengembangan dari sistem tersebut antara lain (Kendall K.E, 2003):

a. Planning

Tahapan pertama atau awal dari perancangan dan pengembangan sistem inventoy ini perencanaan tahap awal yaitu merencanakan waktu pengembangan serta sumber daya yang diperlukan dalam pengembangan sistem inventory ini. dengan model RAD waktu yang dibutuhkan dalam perancangan dan pengembangan sistem informasi ini yaitu 120 hari dengan mengerahkan semua sumber daya yang ada, dalam pemrogrmannya yang diperlukan antara lain Java, PHP, serta pada penggunaan database menggunakan Rest Api (Firdaus, 2007).

b. Analysis

Setelah tahapan planning selesai maka diperlukan analisa terhadap sebuah sistem yang sedang berjalan di sana dengan melakukan wawancara terhadap user agar dapat memenuhi kebutuhan dalam pembuatan sistem ini (Nazir, 2014).

c. Design

Setelah dilakukan analisis terhadap kebutuhan dari pengguna atau user maka dilanjutkan perancangan alur serta proses yang akan dituliskan dalam bentuk use case diagram. layout akan ditampilkan dalam bentuk wireframe program serta untuk basis data akan ditampilkan 
menggunakan Entity Relationship Diagram (ERD).

d. Implementasi Implementasi merupakan tahap akhir di mana user memberikan reaksi dan komentar dalam pengembangan sistem apabila ada kekurangan pada saat penggunaan user dapat memberikan komentar akan kekurangan tersebut dan penulis akan melakukan analisis ulang terhadap sistem ini sampai mencapai sistem yang diinginkan oleh user.

\section{Hasil dan Pembahasan}

Adapun tahapan dalam pembangunan sistem rapid website development, dalam hal ini akan dijelaskan sebagai berikut:

A. Planning

Untuk tahap pertama akan dilakukan Pertemuan dengan beberapa pihak yang bersangkutan, yang berfungsi untuk mencari tau permasalahan atau kebutuhan. Setelah membahas semua permasalahan dan yang dibutuhkan maka kami akan memberi solusi mengenai pengembangan sistem inventori.

B. Analysis

Untuk tahap kedua kami akan melakukan sebuah analisis yang akan dibutuhkan sistem, dari pertemuan sebelumnya. Yang akan kita butuhkan yaitu fungsi administrator, input data barang, satuan, client, supplier, masuk ke gudang dan keluar ke pelanggan. Dan tentunya akan ada informasi pemberitahuan atau report data dan $\mathrm{QR}$ code yang akan di pasang pada setiap barang. Sistem ini akan dibuat berbasis web yang dapat di akses melalui desktop dan android (Sutisna, 2007).
C. Design

Untuk tahap selanjutnya akan dilakukan sebuah, uml, entity relationship diagram tentunya berfungsi untuk perancangan database dan tentunya sebuah template atau design antarmuka.

D. UML

Sebuah rancangan berupa sistem yang akan kita buat, dan akan digambarkan dengan diagram use case yang berupa sebuah interaksi pengguna dengan sistem $(H, 2014)$. Use case tersebut terdiri dari pegawai, admin, kepala gudang, penjelasanya meliputi:

a. Pegawai

Untuk pegawai kali ini hanya bisa menggunakan sebuah fitur di atas yaitu input data barang dan tentunya dapat membuat repot keluar masuk barang.

b. Admin

Untuk admin sendiri hanya bisa mengatur bebrapa pegawai yang dapat dipercaya untuk mengakses superadmin website, agar tidak ada penyalagunaan data.

c. Kepala gudang

Kepala gudang kali ini akan mendatangani surat jalan lalu menambah data masuk dan keluar barang.

E. ERD

Kali ini ada beberapa data yang belum diolah dari laporan faktur yang sangkutpautnya dengan inventaris. Dan tentunya akan digambarkan design database dalam bentuk entiti diagram, sebagai berikut (Yanto, 2016): 


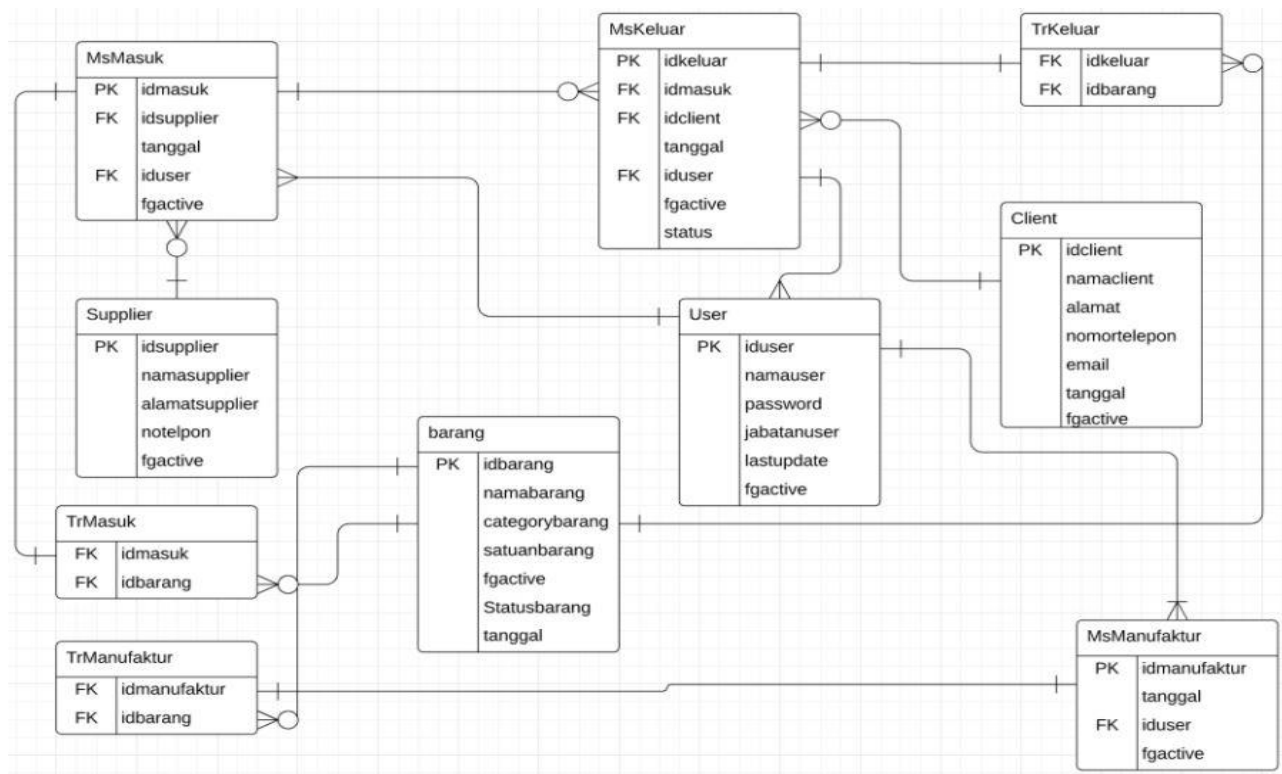

Gambar 2. Entity Relationship Diagram

Entity relationship diagram hubungan antar objek-objek data yang mempunyai hubungan antarrelasi sistem yang akan kami F. Frame kembangkan.
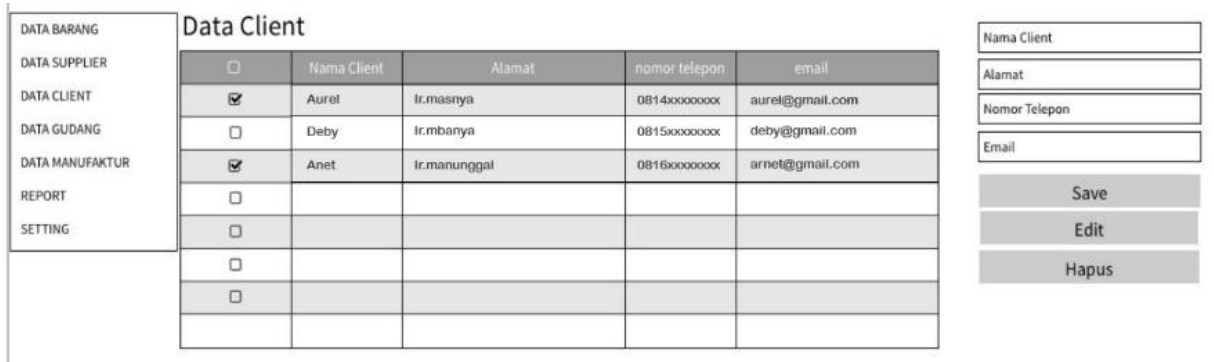

Gambar 3. Data Client

Untuk data client pegawai dapat menginput beberapa data yaitu nama client, alamat, nomor telepon, email. Bagi data yang sudah diinput kemudian dapat disimpan. Selain itu, pegawai dapat mengedit dan menghapus data masukan.
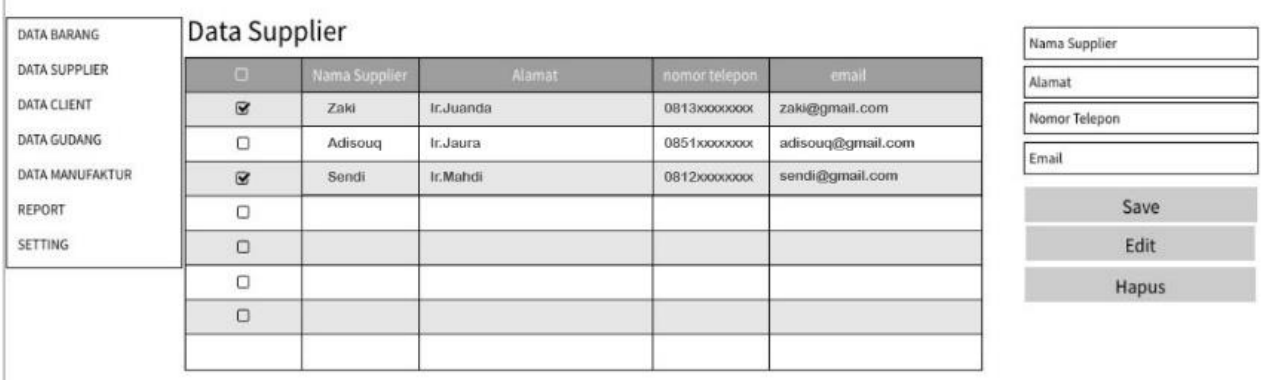

Gambar 4. Data Suplier

Untuk data supplier pegawai dapat menginput beberapa data seperti nama supplier, alamat, nomor telepon, emial. Bagi data yang sudah dimasukkan kemudian dapat disimpan. 
Selain itu, pegawai dapat mengedit dan menghapus data masukan.

\begin{tabular}{|c|c|c|c|c|}
\hline \multirow{2}{*}{$\begin{array}{l}\text { DATA BARQNG } \\
\text { DATA SUPPUER }\end{array}$} & \multicolumn{4}{|c|}{ Data Barang } \\
\hline & ㅁ. & Mama Barane & Category & Satuan \\
\hline \multirow{4}{*}{$\begin{array}{l}\text { DATA CUENT } \\
\text { DATA GUDANG } \\
\text { DATA MANUFARTUR } \\
\text { REPORT } \\
\text { SETTING }\end{array}$} & $\otimes$ & Poxy Normal & Barang Jaal & 1PCS \\
\hline & 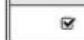 & Poxy Prenium & Barang Jadi & 1PCS \\
\hline & 0 & & & \\
\hline & व & & & \\
\hline & 0 & & & \\
\hline & 0 & & & \\
\hline & & & & \\
\hline
\end{tabular}

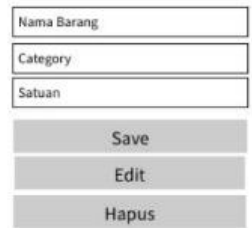

\section{Gambar 5. Data Barang}

Untuk data barang kali ini pegawai dapat menambahkan jenis barang, kategori dan satuan. Bagi data yang sudah dimasukkan kemudian dapat disimpan. Selain itu, pegawai dapat mengedit dan menghapus data masukan.

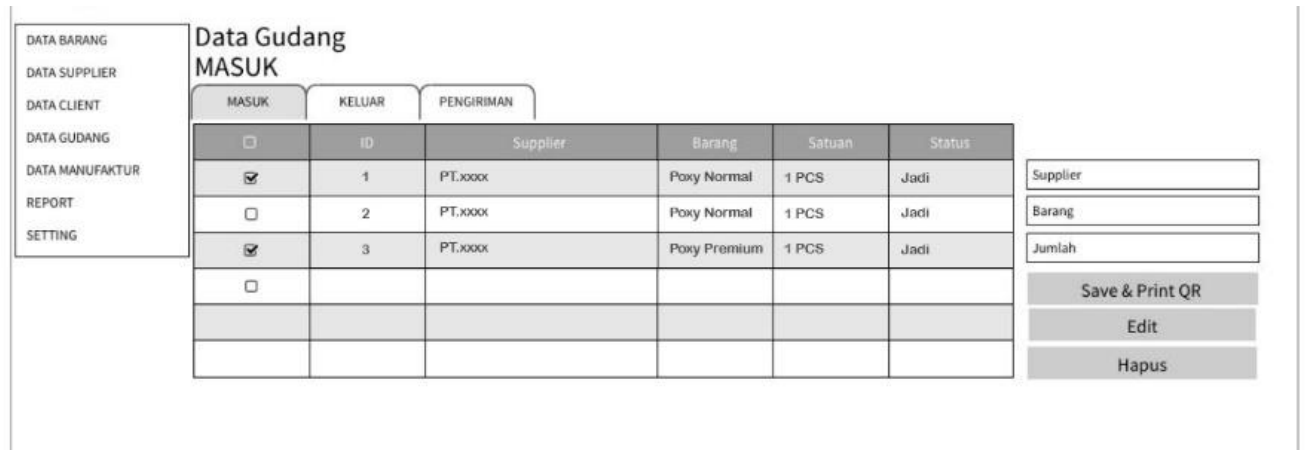

Gamabr 6. Data Gudang

Untuk data gudang, kali ini pegawaidapat menginput data keluar barang, masuk barang ke gudang dan tentunya pengiriman. Kali ini untuk surat jalan dapat di scan dari kode QR untuk pembuatan surat jalan.

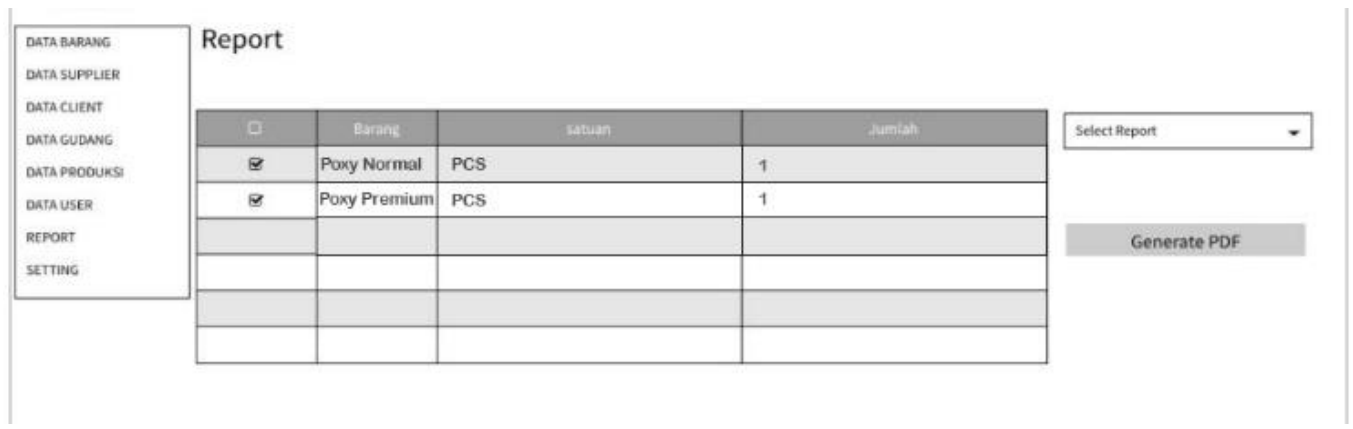

Gambar. 7 Data Report

Pada data report akan tertera data-data barang masuk, keluar dan jumlah pengiriman.

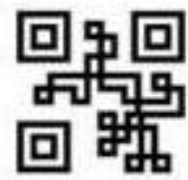

Gambar 8. Scanner 
Pada gambar 8, terdapat kode QR yang dapat di scanner, untuk melihat data keluar, masuk dan pengiriman barang. Setelah di secan maka akan dilakukan pengiriman.

\section{Implementasi}

Untuk tahap ini, setelah website sudah selesai dikembangkan, setelah melalui tahapantahapan sebelumnya, maka akan diuji coba oleh pengembang. Untuk menjamin kualitas sistem/aplikasi yang dikembangkan harus melalui tahap uji coba (Pratala, Asyer, Prayudi, \& Saifudin, 2020). Uji coba merupakan suatu rangkaian aktivitas yang terencana dan sistematis untuk menguji atau mengevaluasi kebenaran fungsi aplikasi berdasarkan desain kasus uji (test case) yang spesifik (Yulistina, Nurmala, Supriawan, Juni, \& Saifudin, 2020). Uji coba terhadap perangkat lunak sangat penting dilakukan dengan tujuan untuk memberikan jaminan kualitas perangkat lunak yang dihasilkan agar bebas dari terjadinya kesalahan (Debiyanti, Sutrisna, Budrio, Kamal, \& Yulianti, 2020).

Setelah diuji coba dan fitur-fiturnya berfungsi dan berjalan dengan baik. Selanjutnya yaitu implementasi dari system prototype menjadi sistem final yang akan digunakan oleh perusahaan.

\section{Kesimpulan}

Berdasarkan hasil pengembangan dan perancangan sistem aplikasi inventori, yang telah di jabarkan oleh kami maka disimpulkan pada perancangan pembuatan sistem inventori gudang PT Indojaya Multi Karya dapat menjadi solusi sebagai sistem informasi mampu membantu membantu pekerjaan secara efisien. Menggunakan metode Rapid Development pada perancangan dan pengembangan sistem tidak memerlukan waktu yang lama, perubahan model, serta design sistem informasi ini dapat disesuaikan dengan berjalannya waktu dan kebutuhan klient. Dengan adanya sistem ini yang dapat diakses dengan mudah serta dapat memberikan informasi mengenai stok persediaan barang kapanpun saat.

\section{Saran}

Dengan dilakukannya perancangan dan pembuatan sistem informasi inventori ini kami mengharapkan agar sistem informasi ini untuk lebih dikembangkan guna menyempurnakan sistem informasi dan mencapai hasil yang memuaskan, perngembangan diharapkan menyajikan sistem dalam fitur android atau pun secara aplikasi dalam desktop sehingga dapat digunakan oleh pengguna lain dan membantu mempermudah pekerjaan secara efisien.

\section{Referensi}

A Aswati, Y. S. (2016). Model Rapid Application Development Dalam Rancangan Bangun Sistem Informasi Pemasaran Rumah. 317324.

Debiyanti, D., Sutrisna, S., Budrio, B., Kamal, A. K., \& Yulianti, Y. (2020). Pengujian Black Box pada Perangkat Lunak Sistem Penilaian Mahasiswa Menggunakan Teknik Boundary Value Analysis. Jurnal Informatika Universitas Pamulang, 5(2), 162-166. doi:10.32493/informatika.v5i2.5446

Firdaus. (2007). Tujuh Jam Belajar Interaktif Php \& MySQL dengan Dreamweaver. 85-88.

H, T. (2014). Analisis serta Perancangan Sistem Informasi melalui Pendekatan UML.

Hidayati, N. (2018). Implementasi Metode Rapid Application Development Dalam Pembangunan Sistem Penerimaan Kas Atas Penjualan. 39-47.

Kendall K.E, K. J. (2003). Analisa dan Perancangan Sistem. 40-55

McLeod. (2001). Management Information Systems. 10-30.

Nazir, M. (2014). Metode Penelitian. Bogor: Ghalia Indonesia.

Pratala, C. T., Asyer, E. M., Prayudi, I., \& Saifudin, A. (2020). Pengujian White Box pada Aplikasi Cash Flow Berbasis Android Menggunakan Teknik Basis Path. Jurnal Informatika Universitas Pamulang, 5(2), 111-119. doi:informatika.v5i2.4713

Pratama, I. P. (2014). Sistem Informasi dan Implementasinya. 20-33.

Sutisna, D. (2007). Tujuh Lagkah Mudah Menjadi Webmaster. 64-88.

Yanto, R. (2016). Manajemen Basis Data Menggunakan MySQL.

Yulistina, S. R., Nurmala, T., Supriawan, R. M., Juni, S. H., \& Saifudin, A. (2020). Penerapan Teknik Boundary Value Analysis untuk Pengujian Aplikasi Penjualan Menggunakan Metode Black Box Testing. Jurnal Informatika Universitas Pamulang, 5(2), 129-135.

doi:10.32493/informatika.v5i2.5366 